\title{
Effect of measurement conditions on measured levels of peak exhaled nitric oxide
}

\author{
C A Byrnes, S Dinarevic, C A Busst, E A Shinebourne, A Bush
}

\begin{abstract}
Background - It is possible to measure nitric oxide (NO) levels in exhaled air. The absolute concentrations of exhaled NO obtained by separate workers in similar patient groups and normal subjects with apparently similar techniques have been very different. A study was undertaken to determine whether changes in measurement conditions alter the concentration of exhaled NO.
\end{abstract}

Method - NO concentrations measured by a chemiluminescence analyser (Dasibi Environmental Corporation) and carbon dioxide $\left(\mathrm{CO}_{2}\right)$ measured by a Morgan capnograph were analysed in single exhalations from total lung capacity in healthy volunteers (mean age 35.9 years). Ten subjects performed five exhalations at four different expiratory flow rates, at four different expiratory mouth pressures, and before and after drinking hot $(n=5)$ or cold $(n=5)$ water. Three subjects performed five exhalations on a day of high background NO (mean NO level $134 \mathrm{ppb}$ ) before and after a set of five exhalations made while both the subject and analysers were sampling from a low NO/NO-free reservoir system.

Results - The mean peak concentration of NO decreased by $35 \mathrm{ppb}(95 \%$ CI 25.7 to 43.4) from a mean (SE) of 79.0 (15.5) ppb at an expiratory flow rate of $250 \mathrm{ml} / \mathrm{min}$ to $54.1(10.7) \mathrm{ppb}$ at $1100 \mathrm{ml} / \mathrm{min}$. The mean peak concentration of NO did not change significantly with change in mouth pressure. The mean (SE) peak NO concentration decreased from $94.4(20.8) \mathrm{ppb}$ to $70.8(16.5) \mathrm{ppb}(\mathrm{p}=0.002,95 \%$ CI 12.9 to 33.1) with water consumption. The mean NO concentration with machine and subject sampling from the low NO reservoir was $123.1(19.4) \mathrm{ppb}$, an increase from results obtained before $\mathbf{( 8 1 . 9}$ (10.2) ppb, $\mathrm{p}=0.001,95 \%$ CI -19.9 to $-62.7)$ and after $(94.2$ (18.3) ppb, $p=0.017$, $95 \%$ CI 6.0 to 51.8) sampling with high ambient NO.

Conclusions - The measurement of exhaled NO must be performed in a carefully standardised manner to enable different teams of investigators to compare results.

(Thorax 1997;52:697-701)

Keywords: exhalation, nitric oxide, airway inflammation.

It is possible to measure nitric oxide (NO) levels in exhaled air in children and adults ${ }^{1-3}$ and these may reflect airway inflammation. ${ }^{4}$ It has been shown that, when compared with normal subjects, the mean levels of $\mathrm{NO}$ in exhaled air are significantly increased in asthmatic subjects who are on bronchodilator therapy as their only treatment. ${ }^{35-7}$ Exhaled NO decreases significantly in asthmatic subjects on regular inhaled topical corticosteroids when compared with those on bronchodilator therapy only. Nitric oxide decreases with regular cigarette smoking, ${ }^{689}$ with ingestion of alcohol, ${ }^{10}$ and may be decreased in subjects with primary ciliary dyskinesia. ${ }^{11}$ Levels have also been shown to increase with viral upper respiratory tract infections. ${ }^{12}$ There is a variation between results seen in men and women with an influence of time of the menstrual cycle affecting the levels obtained in the latter. ${ }^{13}$

However, the absolute mean concentrations of exhaled NO obtained by separate workers in similar patient groups and normal subjects using apparently similar techniques have been quite disparate. In part this could be explained by the different sites of measurement and the degree of contamination of the exhaled air by the nasal and sinus passages. By comparing the concentrations of $\mathrm{NO}$ exhaled during tidal breathing through either nose or mouth, Alving et $a l^{6}$ suggested that the major contribution came from the nasal space with a minor addition from the lower airways. Lundberg $e t a l^{11}$ demonstrated a decreasing concentration of exhaled NO when sampling progressively down the respiratory tract at the nose, mouth and, in four tracheotomised patients, below the vocal cords. By isolating the nasal passages from the rest of the respiratory tract with voluntary closure of the soft palate Kimberly et $a l^{14}$ showed that the release of NO in the nasal passages was approximately seven times greater than the rest of the respiratory tract. Higher levels have now been demonstrated in the paranasal sinuses with an age dependent increase in keeping with sinus pneumatisation. ${ }^{9}$ Gerlach et $a l^{15}$ measured NO concentrations in the nasopharynx and trachea and found higher levels during inspiration than expiration, which suggests that there may be absorption of $\mathrm{NO}$ by the lower respiratory tract but does not exclude the possibility of an exhaled component coming from pulmonary synthesis.

The variation in NO levels obtained makes it difficult to compare results presented by different groups. In a preliminary study in normal adult subjects we were able to demonstrate that peak NO concentrations could be halved if subjects exhaled into a T-piece system ${ }^{16}$ rather than to the NO analyser directly. The possible variables were flow and mouth pressure. We 
had also noticed a variation in NO signal if the subject drank water before exhaling. Another variable which gives cause for concern is the effect of ambient NO levels on the exhaled concentrations measured. The aim of this study was to test different conditions to see which of these factors (expiratory flow rate, expiratory mouth pressure, water consumption, and background NO concentration) altered the exhaled NO concentrations obtained.

\section{Methods}

SUBJECTS

Twenty healthy volunteers (nine men) of mean age 35.9 years (range 18-52 years) took part in the studies. They were non-atopic with no history of respiratory or cardiac disease and were taking no medication. All had normal spirometric values (Compact Vitalograph). Two women smoked two cigarettes per day, the rest were non-smokers.

\section{EQUIPMENT}

Exhaled NO was measured on a chemiluminescence analyser (Dasibi Environmental Corporation) adapted for online recording sensitive to concentrations of $\mathrm{NO}$ from 2 to 4000 parts per billion (ppb). The NO analyser samples at $240 \mathrm{ml} / \mathrm{min}$ with a $95 \%$ response time of 6.4 seconds. Carbon dioxide $\left(\mathrm{CO}_{2}\right)$ levels were measured with a Morgan capnograph sampling at $200 \mathrm{ml} / \mathrm{min}$ with a $95 \%$ response time of 141.5 milliseconds. Mouth pressure was measured by a Medex Straingauge pressure transducer through a Gaeltec pressure amplifier in $\mathrm{mmHg}$ with a $95 \%$ response time of 7.28 milliseconds. Mouth pressure was standardised to $4 \mathrm{mmHg}$ unless otherwise stated. Flow was measured through a Platon flow meter to low flow pneumotachograph and a GM spirometer with a $95 \%$ response time of 40.2 milliseconds. The additional flow measurement was made at $225 \mathrm{ml} / \mathrm{min}$ unless otherwise stated. $\mathrm{NO}$ and $\mathrm{CO}_{2}$ analysers were calibrated using gas mixtures of known composition. Mouth pressure was calibrated by a MX 1000 pressure transducer. The pneumotachograph was calibrated against known flow rates of air from a cylinder. All calibrations were done before and after each subject was studied. The signal for each of these separate measurements was then displayed on a Linseis chart recorder. When comparing measurements allowance was made for the $2 \mathrm{~mm}$ offset of the pens and the time delay for recording of each of the machines.

\section{PROCEDURE}

The method and measurement was an adaptation of the previously described technique by Kharitonov et al. ${ }^{5}$ Each subject performed five slow exhalations from total lung capacity, made consecutively at three minute intervals for each set of conditions. Nose clips were worn five seconds before the exhalation and taken off between measurements. The subjects abstained from food and drink for four hours prior to the experiment. The exhaled NO level recorded was the mean peak $\mathrm{NO}$ concentration of the five exhalations. In our preliminary experiments, ${ }^{17}$ and those of others, ${ }^{5}$ the peak NO concentration has been shown to correlate well with area under the curve. The experiments were made if the ambient level of NO was less than $10 \mathrm{ppb}$ and all inhalation was done from ambient air with the stated exceptions in experiment 4 .

Experiment 1: Effect of expiratory flow rate Ten subjects performed five exhalations at expiratory flows of $250 \mathrm{ml} / \mathrm{min}, 500 \mathrm{ml} / \mathrm{min}$, $750 \mathrm{ml} / \mathrm{min}$, and $1100 \mathrm{ml} / \mathrm{min}$ with a final set of measurements at the first flow to rule out an order effect. Five subjects started with the lowest flow rate and increased their rate with each successive set of five exhalations, and five subjects started with the highest flow rate, decreasing each time. The mouth pressure was kept constant at $4 \mathrm{mmHg}$ by altering a restriction on the flow rotameter which kept this pressure constant at the varying flow rates required.

Experiment 2: Effect of expiratory mouth pressure Ten subjects exhaled at mouth pressures of $4 \mathrm{mmHg}, 8 \mathrm{mmHg}, 12 \mathrm{mmHg}$, and $16 \mathrm{mmHg}$ while maintaining a constant flow of $500 \mathrm{ml} /$ min. This was achieved by altering the restriction in the expiratory tubing at the flow rotameter while the pressure was maintained. Subjects voluntarily maintained the mouth pressure by looking at a pressure gauge. They were randomised to start at the lowest pressure and increase the expiratory pressure with each successive set of five exhalations, or to start at the highest expiratory pressure decreasing each time. All subjects repeated the first set of exhalations at the end of the procedure, as in experiment 1 . In a preliminary experiment calibration gas was applied to the NO analyser at pressures from 4 to $40 \mathrm{mmHg}$ by increments of $4 \mathrm{mmHg}$. Over this range there was an increase in the peak NO signal of $5.6 \mathrm{ppb}^{3}$

\section{Experiment 3: Effect of water consumption}

Baseline measurements were made in 10 subjects at constant mouth pressure $(4 \mathrm{mmHg})$ and constant flow $(500 \mathrm{ml} / \mathrm{min})$. This was followed by measurements made after drinking $60 \mathrm{ml}$ of either hot or cold water (five subjects in each group) 20 seconds prior to exhalation. The subjects then completed a further standard set of five exhalations without any water prior to the manoeuvre.

\section{Experiment 4: Effect of ambient NO level}

In three subjects a set of five measurements was carried out by our standard method with constant mouth pressure $(4 \mathrm{mmHg})$ and flow $(500 \mathrm{ml} / \mathrm{min})$ with the subject breathing ambient air. This was done during a period when the natural background level of $\mathrm{NO}$ was high - above the NO concentration normally meas- 


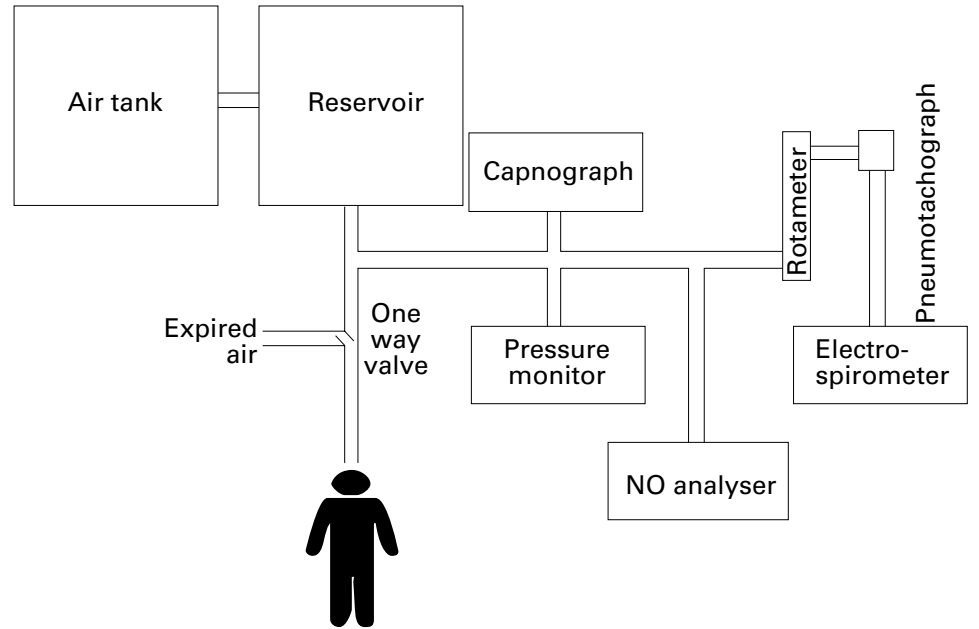

Figure 1 Diagrammatic representation of the reservoir system allowing both machines and subject to sample from a low $\mathrm{NO} / \mathrm{NO}$-free air. $\mathrm{NO}, \mathrm{CO}_{2}$, mouth pressure and flow are all measured.

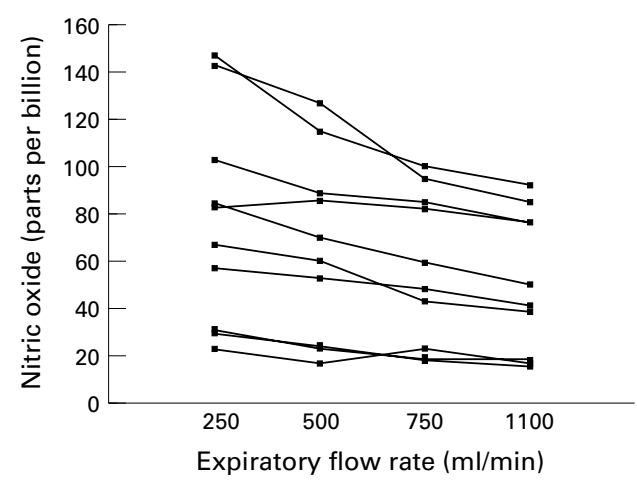

Figure 2 Mean peak exhaled NO concentrations at different expiratory flow rates for 10 individuals. Each point is the mean of five exhalations.

\section{Results}

Experiment 1: Effects of expiratory flow rate The mean (SE) peak concentrations of $\mathrm{NO}$ at the four expiratory flow rate settings were 79.0 (15.5) $\mathrm{ppb}$ at $250 \mathrm{ml} / \mathrm{min}, 67.8$ (13.5) $\mathrm{ppb}$ at $500 \mathrm{ml} / \mathrm{min}, 59.1(11.2) \mathrm{ppb}$ at $750 \mathrm{ml} / \mathrm{min}$, and 54.1 (10.7) $\mathrm{ppb}$ at $1100 \mathrm{ml} / \mathrm{min}$. There were strong linear relations between the NO concentrations obtained at the four flow levels for each individual subject with a correlation coefficient of 0.85 (fig 2). The analysis of variance showed a highly significant difference across the flow rates $(p<0.001)$, with wide variation between the individual subjects. The mean decrease in exhaled NO was $35 \mathrm{ppb}(95 \%$ CI 25.7 to 43.4 ) from the expiratory flow rate of $250 \mathrm{ml} / \mathrm{min}$ to $1100 \mathrm{ml} / \mathrm{min}$. There were no significant differences in the mean $\mathrm{CO}_{2}$ levels, mean mouth pressure, or mean duration of exhalation in the measurements made at the differing flow rates. There was no difference between the first baseline and repeated baseline value of NO when the expiratory flow was the same $(p=0.9,95 \%$ CI -16.9 to 17.0$)$ excluding an order effect.

Experiment 2: Effect of expiratory mouth pressure The mean (SE) peak concentrations of NO obtained at the four mouth pressure settings were $61.0 \quad(15.1) \mathrm{ppb}$ at $4 \mathrm{mmHg}, \quad 55.2$ (12.3) ppb at $8 \mathrm{mmHg}, 47.3(8.4) \mathrm{ppb}$ at $12 \mathrm{mmHg}$, and $40.1(7.2) \mathrm{ppb}$ at $16 \mathrm{mmHg}$. There was no significant difference between the different sets of results. Figure 3 shows that NO levels did not change in most of the patients. However, in two patients who found the higher pressures difficult to sustain there was a fall in NO concentration as mouth pressure increased. There was no difference between the first baseline and repeated final baseline of NO when the mouth pressure was the same ( $p=0.44,95 \% \mathrm{CI}-16.7$ to 15.6$)$, thus excluding an order effect. There was no significant difference between the rate of flow measured at the different mouth pressure readings. The peak expired $\mathrm{CO}_{2}$ at different mouth pressure levels tended to decrease. The mean peak values were $5.90(0.83) \%$ at $4 \mathrm{mmHg}$, $5.83(0.82) \%$ at $8 \mathrm{mmHg}$, and $5.53(0.95) \%$ at $16 \mathrm{mmHg}$. There was also a tendency for 


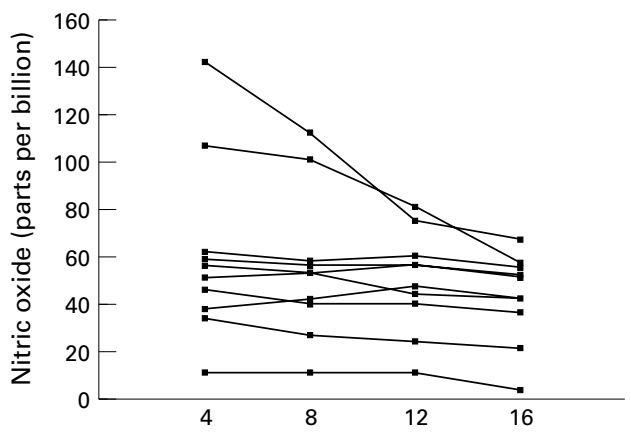

Expiratory mouth pressure $(\mathrm{mm} \mathrm{Hg})$

Figure 3 Mean peak exhaled NO concentrations at different expiratory mouth pressures for 10 individuals. Each point is the mean of five exhalations.

the duration of exhalation to decrease from 49.9 (4.9) seconds at $4 \mathrm{mmHg}, 49.6$ (5.6) seconds at $8 \mathrm{mmHg}, 44.2$ (6.3) seconds at $12 \mathrm{mmHg}$, to 40.9 (5.5) seconds at $16 \mathrm{mmHg}$.

Experiment 3: Effect of water consumption The mean (SE) peak NO concentrations in the 10 subjects was 93.7 (20.8) ppb. This decreased by $23 \mathrm{ppb}(95 \%$ CI 12.9 to 33.1 ) to $70.8(16.5) \mathrm{ppb}(\mathrm{p}=0.002)$ during the measurements made with the subjects drinking $60 \mathrm{ml}$ of water 20 seconds to five seconds before the exhalation. There was then a significant increase of $17 \mathrm{ppb}(95 \% \mathrm{CI}-9.7$ to -24.1 ) to $87.8(8.7) \mathrm{ppb}(\mathrm{p}=0.001)$ in the subsequent recordings made in the standard way. There was no difference in the NO concentrations taken before and after the water experiment $(p=0.095)$. Water temperature did not affect these findings (data not shown).

Experiment 4: Effect of ambient levels of $\mathrm{NO}$ The background concentration of NO during this procedure was 134.5 (11.9) ppb. The mean (SE) background concentration of the reservoir system was $1(0.2) \mathrm{ppb}$. The mean plateau exhaled NO concentration was 123.1 (19.4) ppb in the set of exhalations during which both the machine and subject were sampling from the NO-free reservoir system. This was $41 \mathrm{ppb}$ (95\% CI 19.9 to 62.7 ) greater and $29 \mathrm{ppb}(95 \% \mathrm{CI}-6.0$ to -51.8$)$ greater than the measurements made, respectively, before and after the reservoir system was used. There was no significant difference in the NO plateaus seen before and after the set of exhalations done with the reservoir $(\mathrm{p}=0.27,95 \% \mathrm{CI}-10.9$ to 35.8).

\section{Discussion}

The measurement of exhaled NO is feasible and may reflect airway inflammation. ${ }^{124} \mathrm{~A}$ number of cross-sectional studies of exhaled NO concentrations in different subject groups has been reported. The findings within each research team have been consistent, but the absolute levels of NO between these investigators in the similar subject groups have been very different. All these investigators used a NO chemiluminescence analyser which, although developed by different companies, had similar sensitivities and regular calibration. The study groups were similar. The measurement of NO taken did vary between mean peak exhaled NO, mean plateau exhaled NO, and NO measured during tidal breathing. This led us to suspect that the technique of measurement critically affected the NO levels obtained.

One area of variability is now thought to be the degree of contamination of exhaled NO by nasal and sinus production. This problem has been investigated by a number of other research groups. The measured NO levels have been found to be greatest in the paranasal sinuses with an age dependent increase in keeping with sinus pneumatisation. A progressive decrease in NO concentration has been found when sampling progressively down the respiratory tract from the nasal passages, ${ }^{614}$ oral cavity, ${ }^{15}$ and below the vocal cords. ${ }^{11}$

In a preliminary study on 12 healthy adults ${ }^{16}$ we have shown that the concentration of $\mathrm{NO}$ obtained could be halved depending on whether the subject was breathing directly into the NO analyser (mean $84.8 \mathrm{ppb}$ ) or breathing through a T-piece system (mean $41.2 \mathrm{ppb}$ ). This was also true for the 39 normal children studied with the mean direct NO level being $49.6 \mathrm{ppb}$ and the level with a T-piece of $29.7 \mathrm{ppb}$. The main difference between these two methods was a change in flow from $440 \mathrm{ml} /$ $\min$ to $665 \mathrm{ml} / \mathrm{min}$. We therefore designed these studies to determine what factors altered the concentration of exhaled NO obtained.

In the current study changing the expiratory flow rate significantly altered the mean concentration of NO obtained. The higher the flow rate the lower the concentrations obtained. This finding could be explained by assuming that most $\mathrm{NO}$ is produced proximal to the alveoli. Thus, analogous to a gaseous phase dye dilution, at high flow rates the proximal NO signal from the upper and lower airways is greatly diluted by NO-free (or at least low NO) alveolar gas. The importance of controlling expiratory flow rates is clear cut.

There were no significant differences between the mean exhaled NO concentrations at $4 \mathrm{mmHg}, 8 \mathrm{mmHg}, 12 \mathrm{mmHg}$, and $16 \mathrm{mmHg}$. There was a trend towards differences between the peak $\mathrm{CO}_{2}$ levels reached, being $5.90 \%$ at $4 \mathrm{mmHg}, \quad 5.83 \%$ at $8 \mathrm{mmHg}, \quad 5.83 \%$ at $12 \mathrm{mmHg}$, and $5.53 \%$ at $16 \mathrm{mmHg}$. This may be accounted for by the differences in the duration of exhalation with $49.9 \mathrm{~s}$ at $4 \mathrm{mmHg}$, $49.6 \mathrm{~s}$ at $8 \mathrm{mmHg}, 44.2 \mathrm{~s}$ at $12 \mathrm{mmHg}$, and $40.9 \mathrm{~s}$ at $16 \mathrm{mmHg}$. The differences reflect the difficulty for subjects of maintaining exhalation against a strong resistance at constant flow to generate the higher mouth pressures. Subjects found it tiring to maintain and found it difficult to keep their lips tight around the mouthpiece so as not to allow any air to escape when exhaling. In the lower three pressure settings there was no difference in $\mathrm{NO}, \mathrm{CO}_{2}$, flow, or duration of exhalation. The mouth pressure over the likely range encountered has no relevant effects on the measurements in most 
individuals but two individuals did show an effect. This suggests the need also to standardise mouth pressure.

Exhaled NO levels measured in the standard way (flow set at $500 \mathrm{ml} / \mathrm{min}$, mouth pressure at $4 \mathrm{mmHg}$ ) was $93.7 \mathrm{ppb}$ which decreased significantly to $70.8 \mathrm{ppb}$ when $60 \mathrm{ml}$ of water was drunk between 20 and five seconds before the exhalation. Both the intake of hot and cold water caused a similar decrease in the level of NO. The mechanism of this fall is unknown, but it may be that gut derived NO is responsible for a proportion of the signal.

The background NO concentration is usually low $(<15 \mathrm{ppb})$ but occasionally can be extremely high. In three subjects we showed that there were large differences in the mean exhaled NO concentration obtained depending on the concentration of the NO being inhaled. This finding suggests that measurements of exhaled NO must be done on days with low ambient background NO, or an NO-free circuit should be used such as in our experiment.

The slow expiration time, particularly in the direct measurements, raises the possibility that we are merely recording inspired air contaminated by NO produced from the nose and sinuses and exhaled unchanged. However, use of a faster (T-piece) method does not reveal an abrupt discontinuity suggestive of emptying unchanged dead space prior to measuring true exhaled NO.

In conclusion, several factors critically affect the measured mean peak concentration of exhaled NO. An increase in expiratory flow rate results in a decreased concentration of NO. Although increasing expiratory mouth pressures resulted in no difference in most of the subjects, two showed decreased exhaled NO concentrations. Drinking water just prior to measurement decreases the exhaled NO concentration obtained. A high inspired background level of NO makes the exhaled NO concentrations difficult to interpret. These findings confirm that the measurement of exhaled NO concentrations in humans must be performed in a standard manner for the levels to have any meaning and to enable different teams of investigators to compare results. These findings may account for some of the discrepant results in the literature.

1 Borland C, Cox Y, Higenbottam T. Measurement of exhaled nitric oxide in man. Thorax 1993;48:1160-2.

2 Leone AM, Gustafsson LE, Francis PL, Persson MG, Wikland NP, Moncada S. Nitric oxide is present in exhaled breath in humans: direct GC-MS confirmation. Biochem breath in humans: direct GC-MS conf
Biophys Res Commun 1994;201:883-7.

3 Dinarevic S, Byrnes CA, Shinebourne EA, Bush A Measurement of expired nitric oxide levels in children. Measurement of expired nitric ox

4 Barnes PJ, Belvisi MG. Nitric oxide and lung disease. Thorax 1993;48:1034-43.

5 Kharitonov SA, Yates D, Robbins RA, Logan-Sinclair R, Shinebourne EA, Barnes PJ. Increased nitric oxide in exhaled air of asthmatic patients. Lancet 1994;343:133-5.

6 Alving K, Weitzberg E, Lundberg JM. Increased amount of nitric oxide in exhaled air of asthmatics. Eur Respir f 1993; 6:1368-70

7 Persson MG, Wickland NP, Gustafsson LE. Endogenous nitric oxide in single exhalation and the change during exercise. Am Rev Respir Dis 1993;148:1210-4

8 Schilling J, Holzer P, Guggenbach M, Gyurech D, Marathia $\mathrm{K}$, Geroulanos S. Reduced endogenous nitric oxide in the exhaled air of smokers and hypertensives. Eur Respir $¥$ 1994;7:467-71.

9 Lundberg JON, Farkas-Szallasi T, Weitzberg E, Rinder J, Lindholm J, Anggard A, et al. High nitric oxide production in human paranasal sinuses. Nature Medicine 1995;1: 370-3.

10 Persson MG, Cederquist B, Wiklund CV, Gustafsson LE. Ethanol causes decrements in airway excretion of endogenous nitric oxide in humans. Eur $\mathcal{F}$ Pharmacol Environ Toxicol Pharmacol 1994;270:273-8.

11 Lundberg JON, Weitzberg E, Nordvall SL, Kuylenstierna $\mathrm{R}$, Lundberg JM, Alving K. Primarily nasal origin of exhaled nitric oxide and absence in Kartagener's syndrome. Eur Respir $\mathcal{F}$ 1994; 7:1501-4.

12 Kharitonov SA, Yates D, Barnes PJ. Increased nitric oxide in exhaled air of normal human subjects with upper resin exhaled air of normal human subjects with upper
piratory tract infections. Eur Respir $\mathcal{F}$ 1995;8:295-7.

13 Kharitonov SA, Logan-Sinclair RB, Busst CM, Shinebourne EA. Peak expiratory nitric oxide differences in men or women: relation to the menstrual cycle. Br Heart $\mathcal{F} 1994$ $72: 243-5$

14 Kimberly B, Nejadnik B, Giraud G, Holden WE. Nasal contribution to exhaled nitric oxide at rest and during breathholding in humans. Am F Respir Crit Care Med 1996; 153:829-36.

15 Gerlach H, Rossaint R, Pappert D, Knorr M, Falke KJ Autoinhalation of nitric oxide after endogenous synthesis in nasopharynx. Lancet 1994;343:518-9.

16 Byrnes CA, Dinarevic S, Busst C, Bush A, Shinebourne EA. Is nitric oxide in exhaled air produced at airway or alveolar level? Eur Respir F 1997;10:1021-5.

17 Byrnes CA, Bush A, Shinebourne EA. Measuring expiratory nitric oxide in humans. Methods Enzymol 1996;269(Part b):459-73 